DOI https://doi.org/10.18551/rjoas.2017-03.24

\title{
EXTRACTION AND CHARACTERIZATION OF LYCOPENE FROM TOMATO AND TOMATO PRODUCTS
}

\author{
Hussain M.B., Ahmad R.S., Waheed M., Rehman T.U. \\ Institute of Home and Food Sciences, Government College University, Faisalabad, Pakistan
}

Majeed M.*

National Institute of Food Science and Technology, University of Agriculture, Faisalabad, Pakistan

Khan M.U.

Department of Energy Systems Engineering, University of Agriculture, Faisalabad, Pakistan

Shariati M.A., Plygun S.A., Glinushkin A.P.

All Russian Research Institute of Phytopathology, Moscow Region, Russia

*E-mail: maajidfst@gmail.com

\begin{abstract}
Natural antioxidants have gained immense prominence in recent era for their role in obviating the auto-oxidation of fats, oils and allied food products. Lycopene is categorized among the most anticipated food bioactive molecules owing to its antioxidant activity, which must be extracted from its sources in high quantities. Current project was aimed to compare the conventional (simple solvent extraction) and contemporary (enzyme aided extraction) techniques for lycopene extraction from tomatoes and its products (tomato paste and pulp). Solvent mixture of hexane and acetone (75:25) was applied in both techniques with the initial enzyme (pectinase) application in enzyme aided method. Lycopene content was detected to be significantly high in tomato paste among all the products $(38.3 \%)$ and extraction was more striking through enzyme-aided method. Under optimized conditions, DPPH\% of raw tomatoes $(90.12 \%), \beta$-carotene $(2.74 \%)$ and TPC contents $(40.29 \%)$ in tomato paste were documented high. Conclusively, enzyme aided method for lycopene recovery proved to be more efficient as compared to simple solvent extraction.
\end{abstract}

\section{KEY WORDS}

Tomato, tomato products, pectinase, lycopene, DPPH, $\beta$-carotene, TPC.

In the recent era, tomatoes and its products has gained immense attention owing to the presence of lycopene, a carotenoid pigment, which holds the ability to control numerous ailments like cancer and other degenerative illnesses by hindering the activity of free radicals (Nasir et al., 2014). On-going epidemiological studies reveal that regular intake of tomatoes has an inverse relationship with the danger of developing cancers at various anatomical sites including, the stomach, lung and prostate gland (Viuda-Martos et al., 2014).

Antioxidant ability of lycopene to delocalize free radical species lies in the presence of conjugated carbon-carbon double bonds, which makes it quite beneficial for the human beings. Owing to this, its demand is quite high in food, feed, pharmaceutical and cosmetic industries. Tomatoes and its products (pulp and paste) are regarded as one of the richest sources of lycopene. The amount of lycopene in tomatoes varies between 90 to $190 \mathrm{lg} / \mathrm{g}$ fresh weight (Alda et al., 2009). Tomato paste is a thick concentrate made from the ripened tomatoes with the skin and seeds removed, while, tomato pulp is an unprocessed form, obtained by passing the fresh raw fully red tomatoes from the fine pulper machine removing the seeds (Rodriguez-Azua et al., 2014).

Considerable amount of lycopene is present in the chromoplast of the plant tissues. In tomatoes, its biosynthesis carries on a rapid pace during the ripening process, in which the 
chloroplast transforms into chromoplast. Voluminous sheets of lycopene are present in the outer part of the pericarp while the inner jelly like part mainly contains beta-carotene (Choudhari and Ananthanarayan 2007; Kiokias, 2016).

Owing to the beneficial effects of lycopene, there is a need of time to improve its extraction methods. In the past, simply organic solvents only such as hexane, ethyl acetate, benzene, ethyl ether, acetone, ethanol and petroleum ether etc were used to extract lycopene from its natural sources. Moreover, different combinations of solvents were used to achieve the same objective in more effective way (Periago et al., 2004). These solvents alone or in combinations were not effective in extracting maximum lycopene, as they do not have the power to dissolve the cell wall constituents (cellulose and pectin), mainly responsible for the binding of lycopene (Agarwal and Rao, 2000).

The application of hydrolytic enzymes that degrade and assist in the release of lycopene in high amount is a widely reported method for its efficient extraction. As plant cell wall comprises mainly of cellulose and pectin, but the later mainly binds the lycopene, so pectinase are employed for this purpose. They breakdown the respective bindings and release this important functional component which could be further extracted out by organic solvents (Zuorroa et al., 2011).

The current study was planned for the extraction of lycopene from raw tomato and tomato products (paste and pulp) through solvent and enzyme aided extraction and its characterization through both the methods. Moreover, antioxidant potential of lycopene also determined while using different parameters. i.e. DPPH, TPC and $\beta$-carotene.

\section{MATERIALS AND METHODS OF RESEARCH}

Purchasing of Raw Material and Chemicals. Locally available bright red tomatoes (Solanum lycoperisicum. L) were procured from indigenous market of Faisalabad and stored at $2-4{ }^{\circ} \mathrm{C}$. Fresh tomato products i.e. tomato paste and tomato pulp were prepared according to the prescribed methods.

Pectinase were procured by the Rhizopus species, from Sigma Aldrich. Sodium acetate analytical grade was obtained from Sigma Aldrich. Sodium sulphate was purchased from Merck Millipore. lodine, glacial acetic acid, hexane (AR grade) and acetone were purchased from Merck, Pakistan.

Sample Preparation. The tomatoes were washed under running stream of water to remove all dirt, dust and foreign materials attached to their surface. De-heading and trimming of the tomatoes were carried out manually using a knife. These were processed into tomato paste and pulp. Tomato pulp was obtained by passing the fresh fully red tomatoes through the fine pulper machine and then the seeds and skin were separated following the protocols described by Dauthy (1995). Tomato paste was prepared from ripened tomatoes by removing skin and seeds. It was cooked for several hours and reduced to a thick, red concentrate.

Extraction Method. Two methods were used for the extraction of lycopene from the raw tomatoes and its products. That included simple solvent and enzyme aided extraction methods.

Simple Solvent Extraction. Conventional method involved the simple application of organic solvents to the samples, for lycopene extraction as adopted by Roldan-Gutierrez et al. (2007). The fresh bright red fully mature tomatoes were grinded extensively, while the tomato paste and the pulp were properly homogenized to break the cell structure of these natural food materials for the efficient extraction of lycopene from them. About $20 \mathrm{~g}$ of each sample was taken in the $250 \mathrm{~mL}$ of the conical flask. Then these samples were extracted overnight in the orbital shaker with the solvent mixture of $200 \mathrm{~mL}$ of hexane and acetone in the ratio of 75:25 respectively at room temperature. The extract from each flask was filtered with Whatman No. 1 filter paper. The solvent from extract was separated at $50^{\circ} \mathrm{C}$ in a rotary vacuum evaporator (EYELA, N-N series, Japan) leaving behind crude extract only. The crude extract of each sample was stored at $4^{\circ} \mathrm{C}$ until use. 
Enzyme-aided Extraction. Enzyme-aided extraction is a contemporary technique to acquire beneficial components from natural food materials as followed by (Choudhari and Ananthanarayan, 2007). All the samples (tomato and tomato products i.e. paste and pulp) were first treated with the enzyme pectinase to remove the bindings of pectin, to get the lycopene in the free state for the better extraction latterly by the solvent mixture of hexane and acetone $(75: 25)$. For this purpose, the samples were properly homogenized and grinded extensively according to the requirement. About $3 \mathrm{~g}$ of the grinded sample was taken in 250 $\mathrm{mL}$ of the conical flask. Around $20 \mathrm{~mL}$ of $0.2 \mathrm{M}$ acetate buffer of $\mathrm{pH} 5$ was added to sample in the flask. Main purpose for the addition of the buffer was to provide appropriate environment for enzyme, to work efficiently. After buffer addition, thousand international units of the pectinase were added in the flask and incubated at $60^{\circ} \mathrm{C}$ for 20 minutes. After the completion of incubation process, filtration of the contents was carried out. Filtrate obtained was subjected to solvent extraction using $60 \mathrm{~mL}$ hexane and acetone in the ratio of 75:25 respectively at room temperature. Vortex the contents for proper mixing of filtrate and solvent. Then the extraction was carried out in separating funnel for 15-20 minutes. Upper phase was non-polar in nature comprising lycopene and pooled together while lower aqueous phase was discarded. The crude extract of each sample was stored at $4^{\circ} \mathrm{C}$ until use.

Table 1 - Treatment Plan of the Study

\begin{tabular}{|c|c|c|c|}
\hline & Whole tomatoes & Tomato paste & Tomato pulp \\
\hline $\mathrm{T}_{1}$ & Solvents (Hexane + acetone) & - & - \\
\hline $\mathrm{T}_{2}$ & Pectinase + Solvents & - & - \\
\hline $\mathrm{T}_{3}$ & - & Solvents (Hexane + acetone) & - \\
\hline $\mathrm{T}_{4}$ & - & Pectinase + Solvents & - \\
\hline $\mathrm{T}_{5}$ & - & - & Solvents (Hexane + acetone) \\
\hline $\mathrm{T}_{6}$ & - & - & Pectinase + Solvents \\
\hline
\end{tabular}

Estimation of Lycopene. Lycopene was determined by spectrophotometer following the protocols of Angela et al. (2003). Extract obtained by both treatments (solvent extraction and enzyme-aided extraction) was transferred to the separating funnel. About $20 \mathrm{~mL}$ of $5 \%$ sodium sulphate solution was added in it and shaken gently. This resulted in the formation of the two separating layers in separating flask. Most of the color was noticed in the upper layer. The two phases were separated and the lower aqueous phase was re-extracted with additional $20 \mathrm{~mL}$ solvent. The extract was washed with a small amount of the distilled water. Washed extract containing carotenoids was poured into a brown bottle contain about $10 \mathrm{~g}$ anhydrous sodium sulphate. Resting time of 30 minutes or more was given to it. The extract was decanted into $100 \mathrm{~mL}$ volumetric flask through funnel containing cotton wool. Sodium sulphate slurry was washed with the solvent until it became colorless and washing was transferred to the volumetric flask. The volume was made and absorbance was measured by spectrophotometer at $503 \mathrm{~nm}$ using the petroleum ether as blank.

\section{Absorbance (1 unit) $=3.1206 \mu \mathrm{g}$ lycopene $/ \mathrm{mL}$ Mg lycopene in 100g sample $=31.206 \times$ Absorbance Wt of sample $(\mathrm{g})$}

Antioxidant Activity. Main role of lycopene is its antioxidant activity, apart from its function as a colorant. The extracts obtained from raw tomatoes and its products (pulp and paste) were analyzed for their antioxidant potency through different parameters i.e. free radical scavenging activity (DPPH assay), $\beta$-carotene and total phenolic contents.

Free Radical Scavenging Activity (DPPH Assay). DPPH (1, 1-diphenyl-2-picryl hydrazyl) radical scavenging activity of extracts was measured according to the method of Brand-Williams et al. (1995). An extract of sample of $400 \mu \mathrm{L}$ was added in the test tube to which the $2 \mathrm{~mL}$ of $0.012 \mathrm{M}$ DPPH dissolved in ethanol was added. The solution was then mixed vigorously and allowed to stand at room temperature in the dark for $30 \mathrm{~min}$. The absorbance of mixtures was measured at $517 \mathrm{~nm}$ using a UV-1601 spectrophotometer and 
compared with the control. The experiment was carried out in triplicate. Radical scavenging activity was calculated by the following formula:

$$
\text { Reduction of absorbance }(\%)=[(A B-A A) / A B] \times 100 \text {, }
$$

Where: $A B=$ absorbance of blank sample $(t=0 \mathrm{~min}) ; A A=$ absorbance of tested extract solution ( $\mathrm{t}=30 \mathrm{~min})$.

$\beta$-Carotene Assay. Antioxidant activity based on coupled oxidation of $\beta$-carotene and linoleic acid was evaluated by using a method described by Taga et al. (1984). $1 \mathrm{ml}$ of ßcarotene $(1 \mathrm{mg} / \mathrm{ml}$ in chloroform), $40 \mu \mathrm{L}$ of linoleic acid and $400 \mu \mathrm{L}$ of Tween 80 were transferred to a round-bottom flask. Chloroform from the sample was evaporated using a stream of nitrogen. Then $100 \mathrm{~mL}$ of distilled water was added slowly to the residue and vigorously agitated to give a stable emulsion. To an aliquot of $4.5 \mathrm{~mL}$ of this emulsion, $200 \mu \mathrm{L}$ of the extracted sample was added. To the control reaction mixture $200 \mu \mathrm{L}$ of distilled water was added. Absorbance was measured, immediately at $470 \mathrm{~nm}$. The tubes were placed in water bath at $60^{\circ} \mathrm{C}$ and the absorbance was measured after 0,60 and 120 min time interval respectively.

$$
\begin{gathered}
A A I=A s(0)-A s(120) \\
A b(0)-A b(120)
\end{gathered}
$$

Where: As (0) is absorbance of sample at $0 \mathrm{~min}$, As (120) is absorbance of sample at 120 min. $A b(0)$ is absorbance of blank at 0 min, $A b(120)$ is absorbance of blank at $120 \mathrm{~min}$.

Total Phenolic Contents (TPC). The total phenolic contents in all the extracts were determined by the Folin-Ciocalteu method (Singleton et al., 1999). From the extracted sample, $125 \mu \mathrm{L}$ sample was taken in test tube. Then $500 \mu \mathrm{L}$ distilled water was added in it. After that $125 \mu \mathrm{L}$ of Folin-Ciocalteu reagent was added in it. Resting period of 6 minutes was given to it. Then $1.25 \mathrm{~mL}$ of $7 \%$ sodium carbonate was added in it. Made final volume by adding $1 \mathrm{~mL}$ of distilled water. The samples were given the resting time for 90 minutes for completion of reaction. Took absorbance of the samples in triplicate at $760 \mathrm{~nm}$ by using a UVvis spectrophotometer. Gallic was run as a standard along with the samples and its absorbance was taken at $725 \mathrm{~nm}$. Its solution was prepared by taking $25 \mathrm{mg}$ of gallic acid and dissolved in $25 \mathrm{~mL}$ distilled water. Concentrations of gallic acid up to $450 \mu \mathrm{L}$ were used and its standard curve was used for the calculation of total phenolics in the extract.

Statistical Analysis. The data obtained from each parameter was subjected to statistical analysis to determine the level of significance according to the methods as described by Steel et al. (1997).

\section{RESULTS AND DISCUSSION}

Extraction Methods. The effect of using different extraction methods on lycopene contents from raw tomato and its products is well mentioned in Figure 1. It can be elucidated that the simple solvent extraction method was not significant throughout the process of extraction whereas the enzyme (pectinase) aided extraction showed maximum results for lycopene recovery from all the products. By the solvent extraction method the maximum extraction rate was observed in tomato paste that was $21.3 \mathrm{mg} / 100 \mathrm{~g}$ whereas raw tomatoes and pulp followed by it that was 2.78 and $2.65 \mathrm{mg} / 100 \mathrm{~g}$. On the other hand, enzyme-aided method had remarkable effect on the lycopene extraction rate in tomato paste that was $38.3 \mathrm{mg} / 100 \mathrm{~g}$ whereas pulp had least content of $3.71 \mathrm{mg} / 100 \mathrm{~g}$.

On an average basis, it was obvious from the results that tomato paste proved high in lycopene content by $29.8 \mathrm{mg} / 100 \mathrm{~g}$, owing to the fact that thermal processing (cooking) and mechanical texture disruption (homogenization) of raw tomatoes are convenient ways to enhance bioavailability by breaking down sturdy cell wall structure (pectin), by disrupting chromoplast membranes and cellular integrity, thereby improving the accessibility of lycopene at the initial stage, which eventually helped in the better extraction of lycopene 
contents with enzyme (pectinase) application at the later stage (Zuorroa et al., 2011 ). Enzyme aided extraction method was proved to be more efficient that enhanced the overall lycopene recovery by $6.89 \mathrm{mg} / 100 \mathrm{~g}$ on average basis from all the products. The results of present study are in accordance with the findings of Choudhari and Ananthanarayan, (2007) for the lycopene extraction from tomato and its different fractions, where an increase in the yield of lycopene by $90.6 \mu \mathrm{g} / \mathrm{g}(188 \%)$ was observed in the sample treated with the pectinase. Chena et al. (2011) verified that the extraction of flavonoids from the Ginkgo biloba leaves with the aid of enzymes showed an increase of $102 \%$ in extraction efficiency than simple solvent extraction method.

Table 2 - Mean values of DPPH, TPC and ß-carotene contents through solvent extraction method, \%

\begin{tabular}{|c|c|c|c|}
\hline Parameter & Raw Tomato & Tomato Pulp & Tomato Paste \\
\hline DPPH & $87.9 \pm 0.38$ & $56.9 \pm 0.20$ & $73.77 \pm 0.05$ \\
\hline TPC & $38.95 \pm 0.30$ & $33.84 \pm 0.07$ & $37.85 \pm 0.03$ \\
\hline ß-carotene & $1.28 \pm 0.03$ & $0.77 \pm 0.03$ & $1.56 \pm 0.05$ \\
\hline
\end{tabular}

Table 3 - Mean values of DPPH, TPC, ß-carotene Contents through enzyme-aided solvent extraction method, \%

\begin{tabular}{|c|c|c|c|}
\hline Parameter & Raw Tomato & Tomato Pulp & Tomato Paste \\
\hline DPPH & $90.12 \pm 0.05$ & $66.99 \pm 0.14$ & $79.56 \pm 0.05$ \\
\hline TPC & $43.70 \pm 0.06$ & $37.85 \pm 0.05$ & $42.75 \pm 0.05$ \\
\hline B-carotene & $1.77 \pm 0.06$ & $1.23 \pm 0.04$ & $2.74 \pm 0.04$ \\
\hline
\end{tabular}

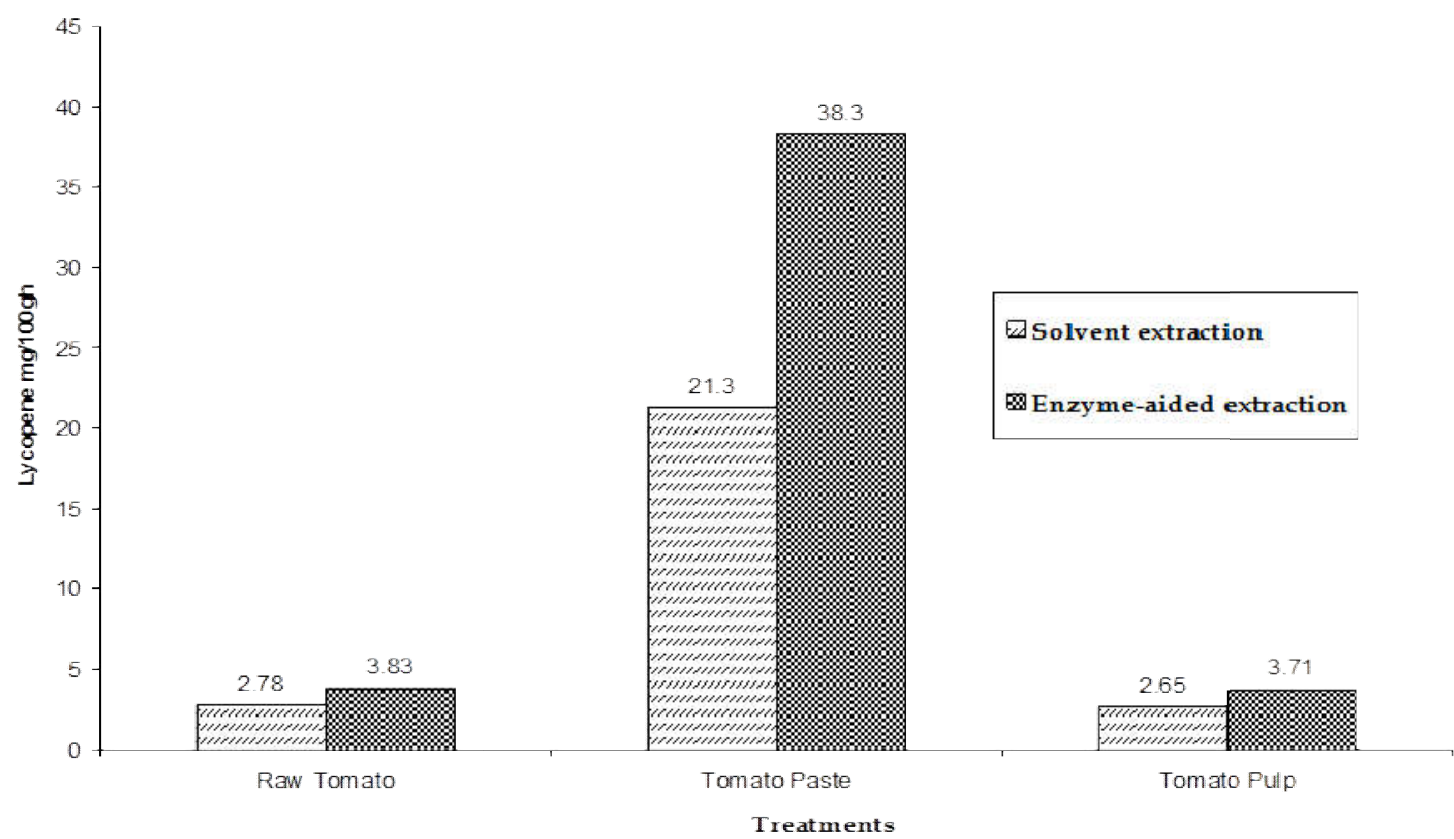

Figure 1 - Effect of solvent and enzyme-aided extraction on lycopene contents from raw tomato and tomato products

DPPH free radical scavenging activity. DPPH free radical scavenging activity is one of those indicators, which are important in determining antioxidant potential of selected bioactive molecules or extract containing them. It is elucidated from Figure 2 that the free radical scavenging activity was found to be maximum in the enzyme-aided extract of raw tomato which was $90.12 \%$ than the solvent extract in which it was found to be $87.9 \%$. In case of tomato products, there was a maximum radical scavenging activity in tomato paste of $79.55 \%$ was observed than the tomato pulp which was $66.98 \%$ from enzyme-aided extraction. 


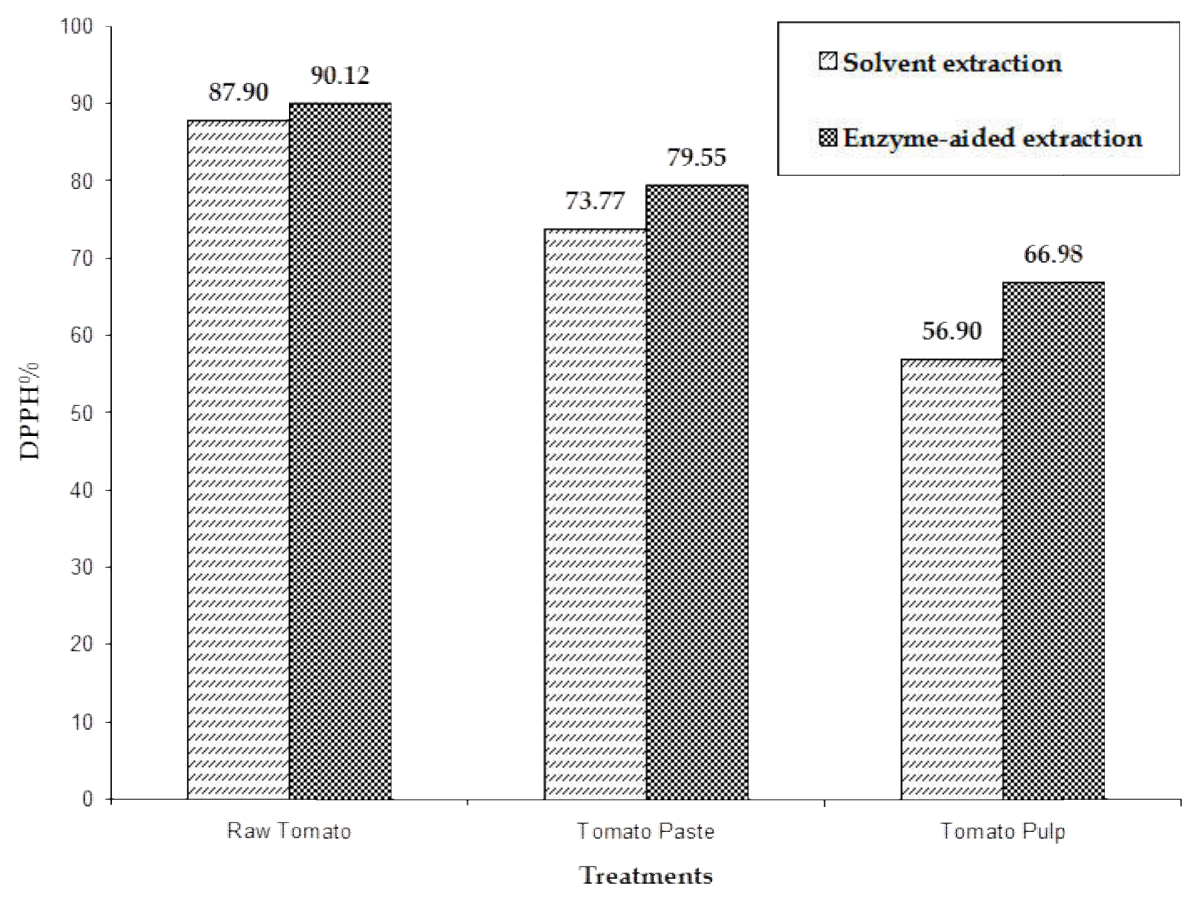

Figure 2 - DPPH \% from raw tomato and tomato products extract

The results of free radical scavenging assay are in accordance with findings of Lu and Chen (2008) who verified that the tannase enzyme treated green tea was exhibiting $62 \%$ higher DPPH (2,2-diphenyl-1-picrylhydrazyl) scavenging effects than the untreated ones.

$\beta$-carotene contents. $\beta$-carotene is the molecule that gives red color to the tomato. It also has antioxidant properties and may help in preventing cancer and other diseases. As mentioned in Table 2 and 3 , the tomato paste had $2.74 \mathrm{mg} / 100 \mathrm{~g} \beta$-carotene contents by enzyme-aided extraction while it was $1.56 \mathrm{mg} / 100 \mathrm{~g}$ by solvent extraction, since the extraction method had significant effect on the $\beta$-carotene content.

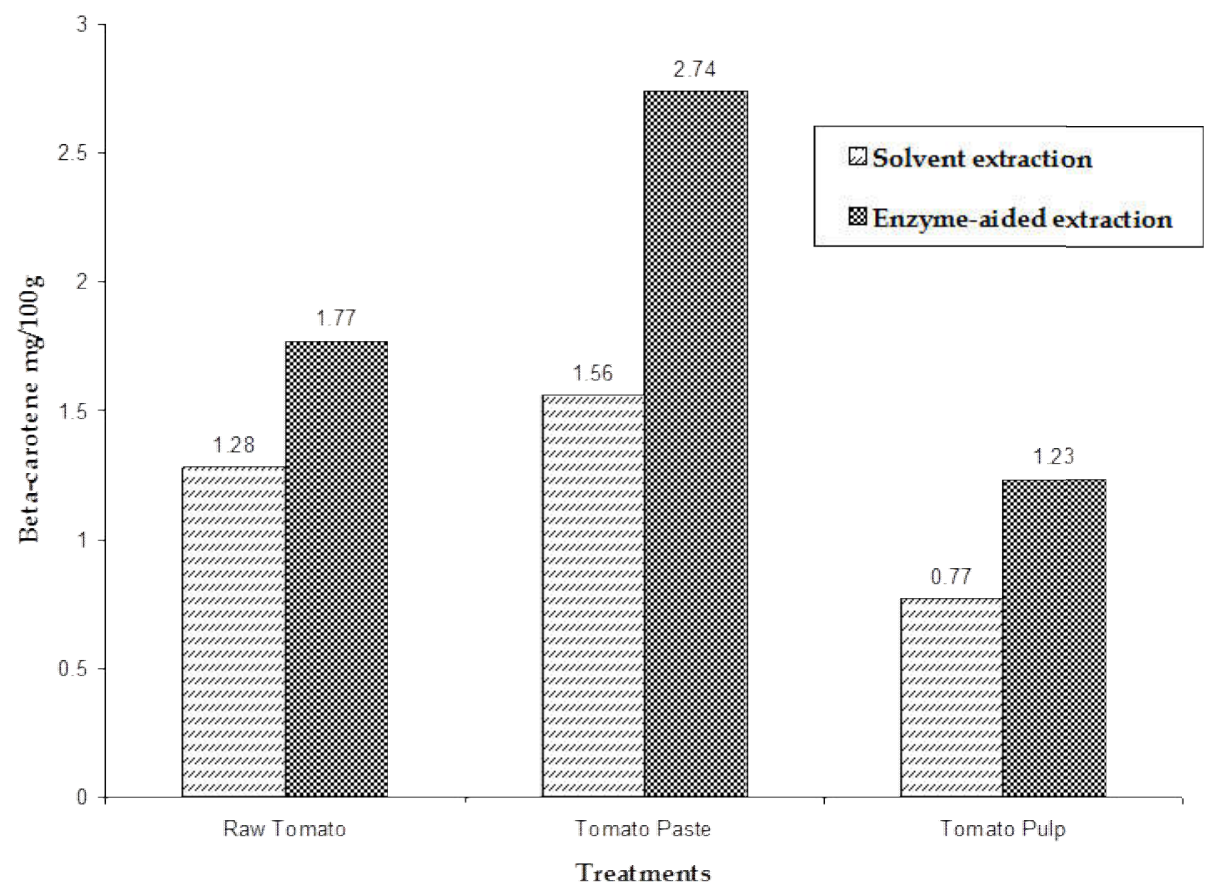

Figure $3-\beta$-Carotene contents $\mathrm{mg} / 100 \mathrm{~g}$ from raw tomato and tomato products extract 
As shown in Figure 3, in raw tomato and tomato pulp these were $1.77 \mathrm{mg} / 100 \mathrm{~g}$ and $1.23 \mathrm{mg} / 100 \mathrm{~g}$ respectively by enzyme-aided method. By solvent extraction these contents were found to be $1.28 \mathrm{mg} / 100 \mathrm{~g}$ and $0.77 \mathrm{mg} / 100 \mathrm{~g}$ raw tomato and tomato products. Present findings were well supported by the findings of Baranska et al. (2006), who noted that $\beta$ carotene occurred in tomato fruits and various tomato products is $0.23-2.83 \mathrm{mg} / 100 \mathrm{~g}$.

Total phenolic contents. Mean values of the total phenolic contents is presented in Table 2 and 3 . For whole tomatoes, the value for the total phenolic contents by enzymeaided method was found to be $43.70 \mathrm{mg}$ GAE/ $100 \mathrm{~g}$, and for the tomato paste $42.74 \mathrm{mg}$ GAE/100g.

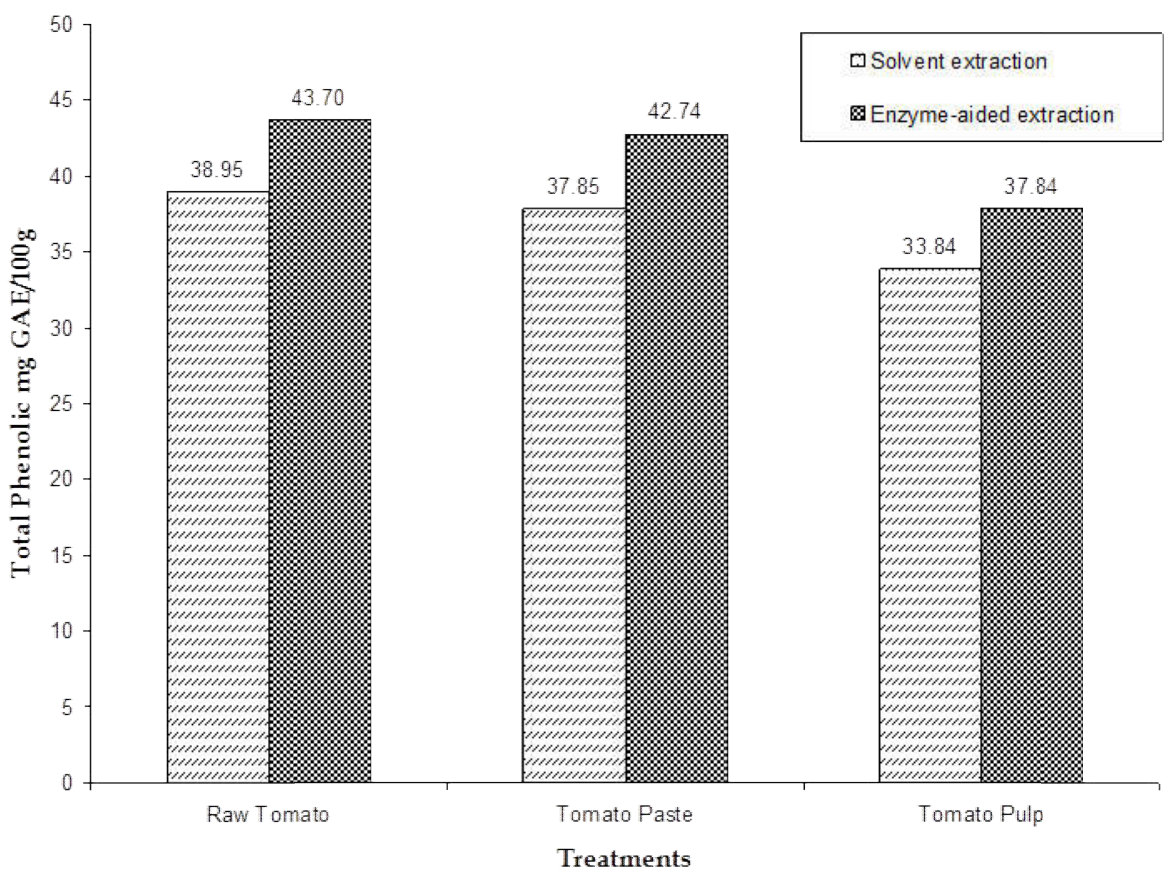

Figure 4 - Total phenolic content from raw tomato and tomato products extract

Overall, as depicted by the Figure 4, the total phenolic contents were found in maximum amount in raw tomato than its products and extraction was more pronounced by the enzyme-aided method. George et al. (2004) reported that the phenolic content in different tomato genotypes ranged from $10-40 \mathrm{mg}$ catechin equivalents $/ 100 \mathrm{~g}$, and in pulp the phenolic contents ranged from $9-27 \mathrm{mg}$ catechin equivalents $/ 100 \mathrm{~g}$.

\section{CONCLUSION}

The present project was designed to evaluate the competency of enzyme aided extraction over simple solvent extraction, to take out the antioxidants from tomato and its products, and also to study the antioxidant activity of extracts obtained by both methods. There was a significant difference between the yields of the lycopene, extracted with enzyme aided extraction than the simple solvent extraction method. The maximum amount of lycopene was recovered from tomato paste by enzyme (pectinase) aided method, which had the ability to break down the bindings of pectin responsible for the lycopene capturing in the cell. Significant differences in the antioxidant potency of the different extracts were observed as a function of both types of extraction methods. Enzyme aided extracts were found to be at the top position with regard TPC, ß- carotene assay and free radical scavenging activity, followed by simple solvent extracts. In brief, the whole investigation can be concluded as extraction of lycopene in the presence of pectinase enzyme speeds up as well as improves the amount of lycopene recovery. 


\section{REFERENCES}

1. Agarwal, S and A.V. Rao. 2000. Carotenoids and chronic diseases. Drug. Metab. Drug. Interact. 17: 189-210.

2. Alda, L.M., I. Gogoasa, B. Despina-Maria , I. Gergen, S. Alda, C. Moldovan and L. Nita.2009.Lycopene content of tomatoes and tomato products. Journal of Agroalimentary Processes and Technologies 2009, 15 (4), 540-542.

3. Angela, R.D., W. F. Wayne and P.V. Penelope. 2003. A rapid spectrophotometric method for analyzing lycopene content in tomato and tomato products. Postharvest. Biol.Tec. 28: 425-430.

4. Baranska, M., W. Schu1tze and H. Schulz. 2006. Determination of Lycopene and ßcarotene content in tomato fruits and related products: Comparison of FT-Raman, ATRIR, and NIR Spectroscopy. Anal Chem. 78: 8456-8461.

5. Brand-Williams, W., M.E. Cuvelier and C. Berset. 1995. Use of a free radical method to evaluate antioxidant activity. Lebensm-Wiss. Technol. 28: 25-30.

6. Chena, S., X.H. Xinga, J.J. Huangb and M.S. Xub. 2011. Enzyme-assisted extraction of flavonoids from Ginkgo biloba leaves: Improvement effect of flavonol transglycosylation catalyzed by Penicillium decumbens cellulose. Enz Micr Technol. 48:100-105.

7. Choudhari, S.M and L. Ananthanarayan. 2007. Enzyme aided extraction of lycopene from tomato tissues. Food Chem. 102: 77-81.

8. Dauthy, M.E. 1995. Fruit and vegetable processing. Food and Agriculture Organization of the United Nations, Rome.

9. George, B., C. Kaur, D. S. Khurdiya and H.C. Kapoor. 2004. Antioxidants in tomato (Lycopersicon esculentum) as a function of genotype. Food Chem. 84: 45-51.

10. Kiokias, S., C. Proestos and T. Varzakas .2016. A Review of the Structure, Biosynthesis, Absorption of Carotenoids-Analysis and Properties of their Common Natural Extracts. Curr Res Nutr Food Sci. doi:http://dx.doi.org/10.12944/CRNFSJ.4.Special-Issue1.03

11. Lu, M.J and C. Chen. 2008. Enzymatic modification by tannase increases the antioxidant activity of green tea. Food Res Int. 41:130-137.

12. Nasir, M.U., S. Hussain and S. Jabbar . 2014. Tomato processing, lycopene and health benefits: A review. Sci Lett;3(1): Onlie first 20140038-SL.

13. Periago, M.J.S., F. Rincoa, M.D. Aguera and G. Ros. 2004. Mixture Approach for Optimizing Lycopene Extraction from Tomato and Tomato Products. J. Agric. Food Chem. 52: 5796-5802.

14. Rodriguez-Azua, R., A. Treuer, R. Moore-Carrasco, D. Cortacans, M. Gutierrez, L. Astudillo, E. Fuentes and I. Palomo. 2014. Effect of tomato industrial processing (Different hybrids, paste, and pomace) on inhibition of platelet function in vitro, ex vivo and in vivo. J. Med. Food. 17 (4): 505-511.

15. Roldan-Gutierrez, J.M and M.D. Luque de Castro. 2007. Lycopene: The need for better methods for characterization and determination. Trends in Anal. Chem. 26: 163-170.

16. Singleton, Y.L and J.A. Rossi. 1999. Colorimetry of total phenolics with phosphomolybdic-phosphotungestic acid reagent. Am J. Enol Vitic. 16: 144-158.

17. Steel, R. G. D., J.H. Torrie and D. Dickey. 1997. Principles and procedures of statistics. A biometrical approach. 3rd ed. McGraw Hill Book Co Inc. New York.

18. Taga, M.S., E.E. Miller and D.E. Pratt. 1984. China seeds as source of natural lipid antioxidation. J. Am. Oil Chem. Soc. 61: 928-931.

19. Viuda-Martos, M., E. Sanchez-Zapata, E. Sayas-Barbera, E. Sendra, J.A. Perez-Alvarez and J. Fernandez-Lopez. 2014. Human health benefits of lycopene and its application to meat products: a review. Crit Rev Food Sci Nutr. 54(8):1032-1049.

20. Zuorroa, A., M. Fidaleob and R. Lavecchiaa. 2011. Enzyme-assisted extraction of lycopene from tomato processing waste. Enz Micr Technol. 49(6-7): 567-573. 